\title{
NOTES ON THE MEASUREMENT OF HIGH VOLTAGE
}

\author{
BY WILLIAM R. WORK
}

Abstract of Paper

A briet account is given of some experiments made to determine the relative accuracy of certain methods used in measur: ing high voltages.

The methods comprise the use of a tertiary (or voltmeter) coil in the high-tension transformer, the direct measurement of voltage by a crest voltage meter and the derivation of the high-tension pressure from the primary voltage.

IN MOST commercial and experimental tests employing high voltage a knowledge of the crest or peak value of the voltage is of the first importance. Often this crest value may be determined quite satisfactorily by a gap method. In other cases (dielectric tests on cables, etc.,) the use of a sparkgap is not desirable because the discharge of the gap may set up oscillations which will over-stress the dielectric thereby permanently injuring or even puncturing it. ${ }^{1}$ There are other well known disadvantages attendant on the use of a spark-gap as a voltmeter. Several methods for the measurement of high voltages which are free from the objections peculiar to the spark gap have been used.

This paper is an account of some tests which were made with the view of comparing these methods among themselves and with a spark gap.

\section{Experimental Apparatus}

The generator used is a $60-\mathrm{kv}$-a., 250-volt, eight-pole, 60cycle, three-phase alternator with both ends of each phase winding brought out to the terminal board. In these tests the excitation was kept substantially constant at normal value and three schemes of connection were used giving three different classes of voltage waves. These schemes will be designated Supply $A$, Supply B and Supply $C$ respectively.

1. Voltage Testing of Cables, Middleton and Dawes, Trans. A.I.E.E., Vol. XXXIII, 1914, p. 1185. 
Supply A. Windings connected in Y. Wave shape approximating a sine form. See Fig. 1.

Supply B. One-phase winding alone. Prominent third harmonic with other harmonics giving a flat-topped wave. See Fig. 1.

Supply $C$. Two windings connected in V. Same fundamental as Supply $B$ but the third and ninth harmonics are doubled in value and the wave has a prominent hollow at the quarter-cycle point. See Fig. 2.

The transformer has a capacity of $100 \mathrm{kv}-\mathrm{a}$. at 200,000 volts, 60 cycles. One end of the high-tension winding was grounded. The. primary winding consists of four separate 480 -volt coils arranged to be connected in parallel, in series-parallel or in series. The reactance drop is about 4.5 per cent, the resistance

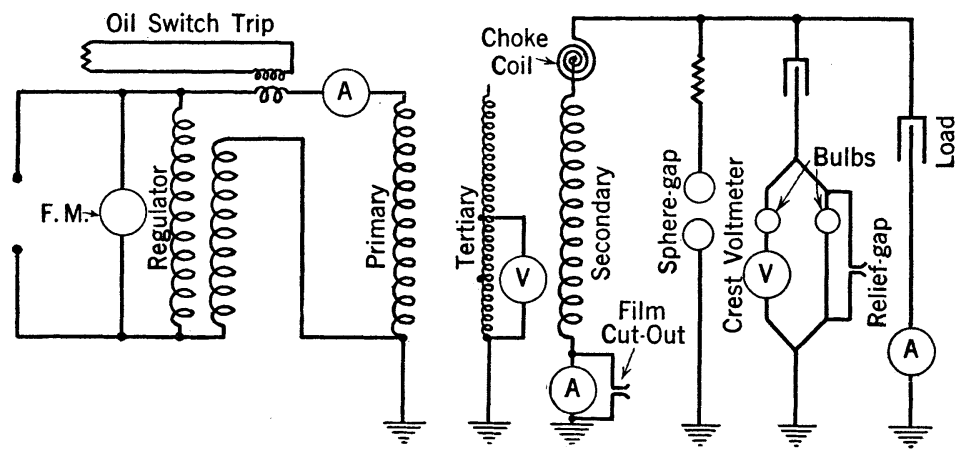

FIG. 4

drop about 0.6 per cent. Due to the capacitance of the hightension winding the no-load power factor of the transformer is high, varying from about 99 per cent to about 96 per cent, over the range of voltage used in these tests. The transformer had been equipped with a tertiary, or voltmeter, coil intended to serve as a means of determining the secondary voltage. This coil has taps brought out at 25 per cent and at 50 per cent of the winding. The accuracy with which the secondary voltage could be determined by the use of this coil was one of the things investigated.

Control of the voltage was obtained by a $50-\mathrm{kv}-\mathrm{a}$., 60 -cycle induction regulator with which the pressure applied to the transformer primary could be varied from zero to twice the generator voltage in a satisfactory manner. 


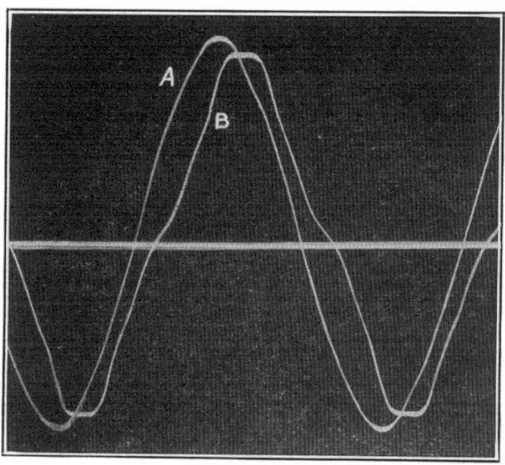

[WORK]

Fig. 1-No-Load Wave Forms of Supplies A AND B

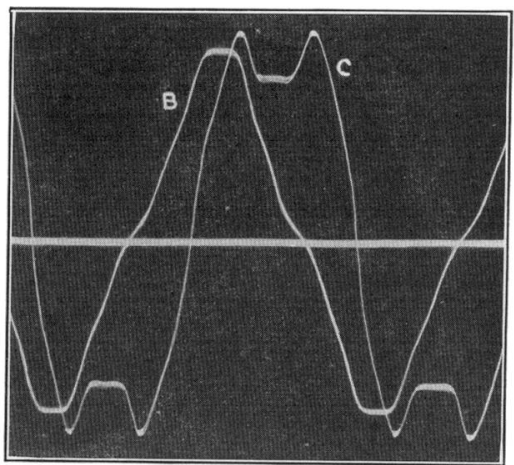

[WORK]

Fic. 2-No-LoAd Wave ForMS OF Supplies B AND C

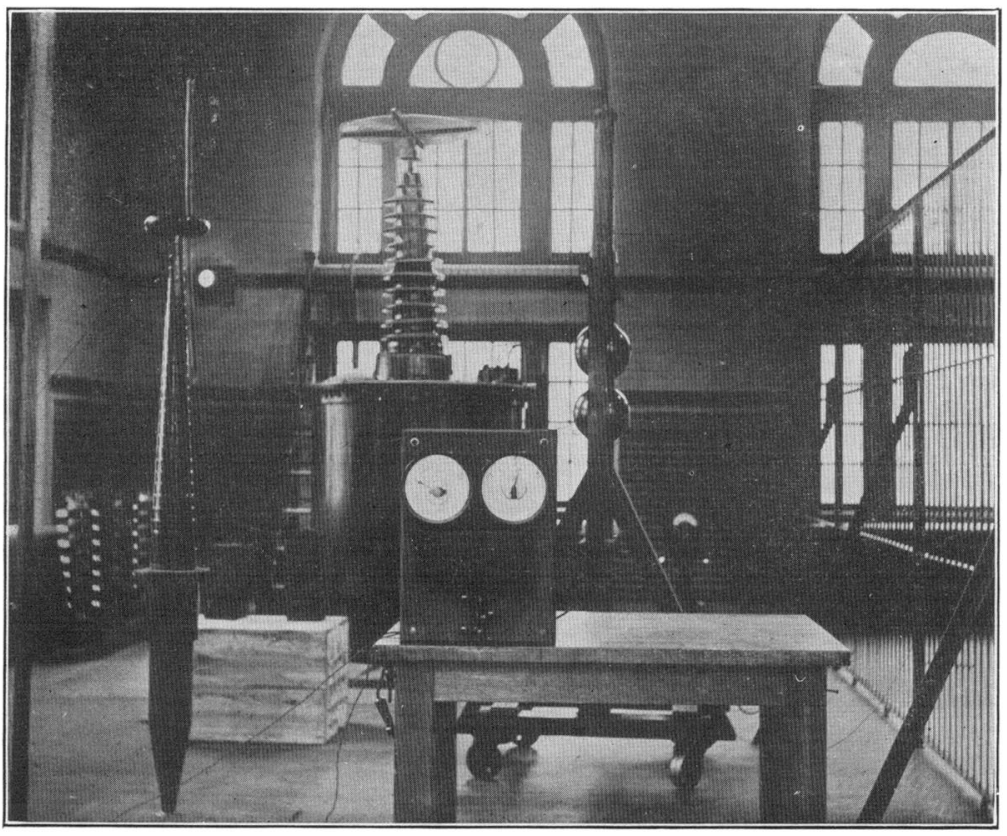

[WORK]

Fig. 3-Transformer, Sphere Gap and Crest Voltage Meter 
Voltmeters of the electrodynamometer type were used, all being checked against the same precision voltmeter. The larger secondary currents were measured by a hot-wire ammeter; smaller currents, by voltmeters used as ammeters.

For the tests with condensive load, sixty $\frac{1}{4}$-mf., 2000-volt condensers were available. These were used in two different combinations, viz., all in series, and thirty in series, two in parallel.

The actual secondary voltage was determined by a standard 250-mm. sphere gap. The relation between the length of gap and voltage and the correction for air density as specified in the Standardization Rules of the Institute were used. Incidentally, the air density correction factor, $k$, for $250-\mathrm{mm}$. spheres, corresponding to a barometric pressure of $b \mathrm{~mm}$. and an air temperature of $t$ deg. cent., can be expressed as a function of $b$ and $t$ thus: ${ }^{2}$

$$
k=\frac{0.366 b}{273+t}+0.066
$$

In most of the tests the gap was set at a certain length and the voltage slowly raised until spark-over occurred; in some cases, however, the gap was shortened slowly with the voltage constant. There was little difference in the results obtained by the two methods of manipulation although the first method gave slightly more consistent results and was therefore preferred. In using the gap a set of observations was considered good only when the voltmeter (on the tertiary coil) indicated stable conditions at the moment of breakdown. Each point is the mean of five to seven trials.

\section{Determination of Crest Factors}

Polar oscillograms of the voltages and currents were taken and the first six odd harmonic components of the waves were determined by a mechanical analyzer. ${ }^{3}$ The crest values were then obtained by calculating the ordinates of the waves at a few degrees on either side of the angle at which an inspection of the oscillogram indicated the peak. The crest values thus determined from the harmonic components were checked by direct measurement of the amplitudes on the oscillograms.

2. Derived from Peek's eq. (4), p. 931, Trans. A.I.E.E., Vol. XXXIII, 1914.

3. Electric Journal, Feb. 1914, May, 1914. 
TABLE I-SECONDARY VOLTAGE DERIVED FROM TERTIARY VOLTAGE

(Secondary pressure derived from the observed tertiary voltage and expressed as the r. m. s. value of the sine wave of equal peak.)

Ratio of secondary turns to tertiary turns $=1000: 1$

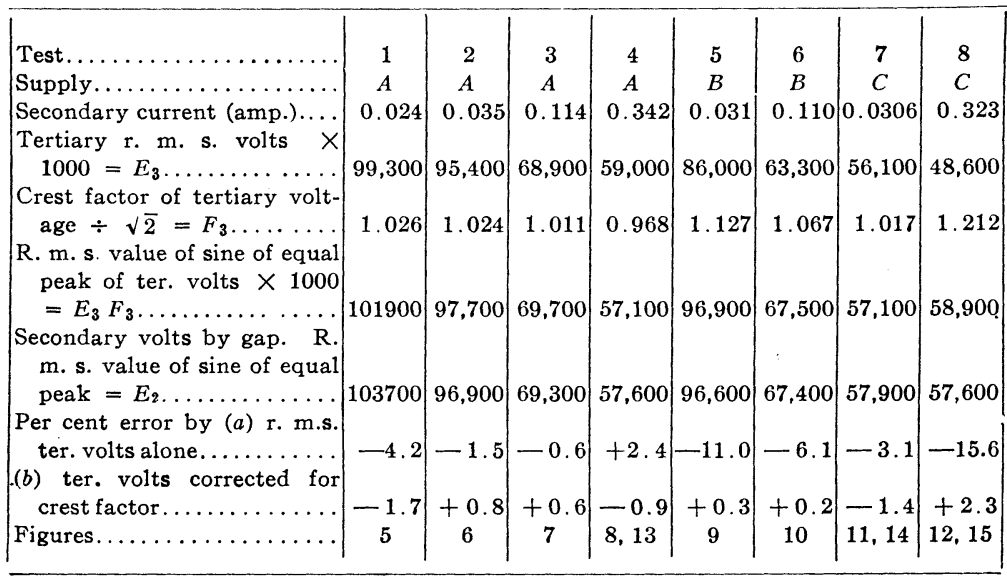

An inspection of the above data shows that the tertiary voltage corrected for crest factor is a satisfactory measure of the actual secondary voltage as determined by a sphere gap.

Obviously the r.m.s. value of the tertiary voltage should not be used alone as a measure of the secondary voltage, when the latter is defined in terms of the crest value, unless something is known about the crest factor. The wave shape of the secondary voltage depends upon so many factors of complex relationship that it is practically impossible to predict how the crest factor will be changed by a given change in the conditions of load or supply. The condensive character of the usual load in combination with one or more of the several inductances of the system may result in the amplification of one of the higher harmonics through partial, if not full, resonance, or it may result in suppression of the higher harmonics. Magnetic saturation in the generator, control apparatus and the transformer plays an important part in wave distortion, while corona, by changing the value and phase of the current, may contribute to the effect through generator reactions.

In this connection it is interesting to study the oscillograms and the crest factors of the voltage waves. In tests 1 to 4 (Figs. 5 to 8 ) the generator was connected to give a "good" e.m.f. wave (Supply $A$ ). As the load was increased the tertiary voltage wave shape changed from a peaked form to a 
PLATE III.

A, I, E, E,

VOL. $X X X V, 1916$

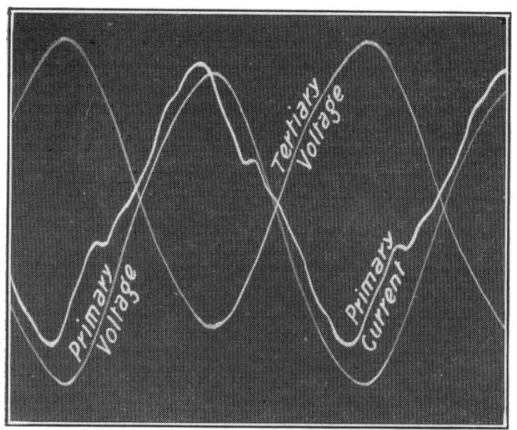

Fig. 5-Test No. 1

[WORK

Crest factor of primary voltage $=1.421$

Crest factor of tertiary voltage $=1.451$

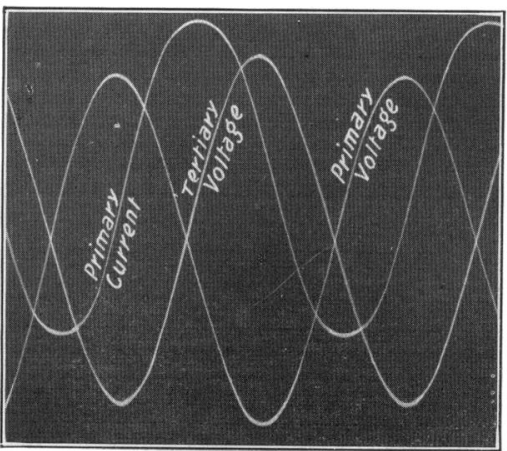

Fig. 7-Test No. 3

[WORK]

Crest factor of primary voltage $=1.424$

Crest factor of tertiary voltage $=1.430$

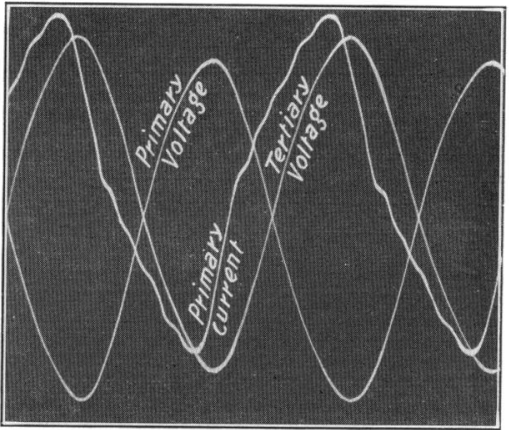

[WORK]

Fig. 6-Test No. 2

Crest factor of primary voltage $=1.434$

Crest factor of tertiary voltage $=1.448$

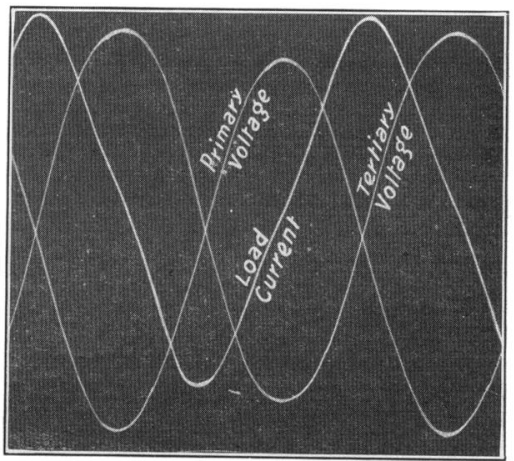

Fig. 8-Test No. 4

[WORK]

Crest factor of primary voltage

Crest factor of tertiary voltage

$=1.414$ 
PLATE IV.

A. I. E, E.

VOL. $X X X V, 1916$

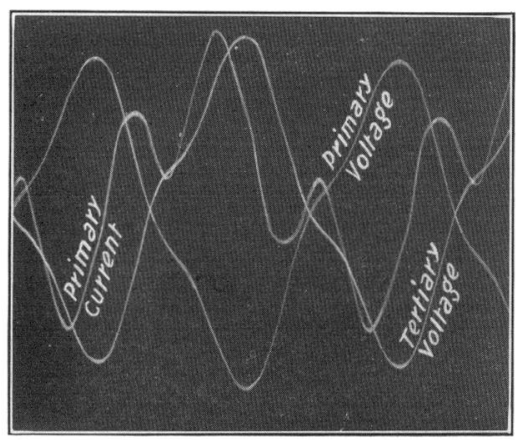

Fig. 9-Test No. 5

Crest factor of primary voltage $=1.581$ Crest factor of tertiary voltage $=1.593$

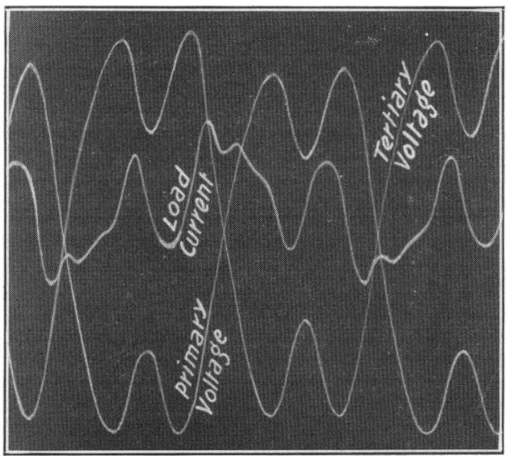

Fig. 11-Test No. 7

Crest factor of primary voltage Crest factor of tertiary voltage

Crest factor of integral of load current
[WORK]

$=1.399$

$=1.438$

$=1.528$

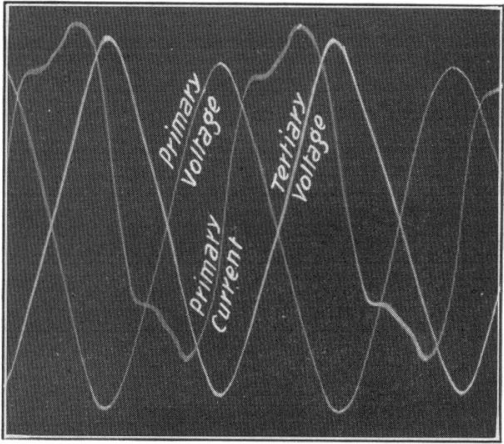

FIg. 10-Test No. 6

Crest factor of primary voltage $=1.474$

Crest factor of tertiary voltage $=1.509$

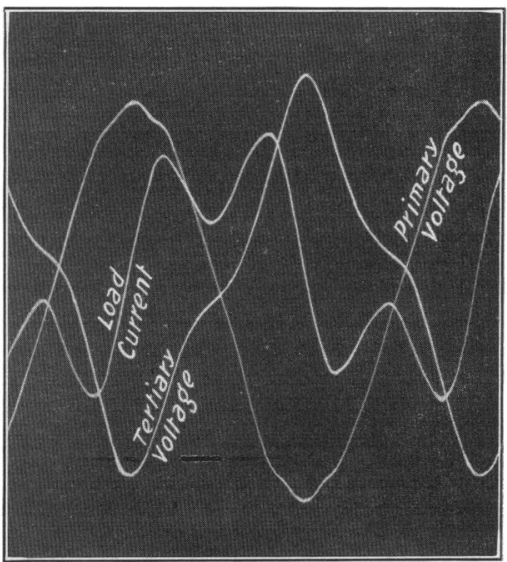

Fig. 12-Test No. 8

[WORK]

Crest factor of primary voltage

Crest factor of tertiary voltage

$=1.714$

Crest factor of integral of load current $=\mathbf{1} .655$ 
flat-topped form, the crest factor varying apparently as a linear. function of the secondary current. In tests 5 and 6 (Figs. 9 and 10) Supply B was used. The chief impurity in these tertiary wave shapes is the third harmonic. This component was 19.2 per cent of the fundamental with the lighter load but only 6.5 per cent with the heavier load, the resulting change in the crest factor being from 1.593 to 1.509 . The addition of load here reduced the crest factor. Figs. 11 and 12 (tests 7 and 8 ) are especially interesting in that they show great changes in wave shape and crest factor produced by simply changing the load. The chief impurity in the tertiary wave shape is again the third harmonic. Here an increase in the load lowered this component in value from 36 per cent to 24 per cent, and, what is of more importance, practically reversed its phase, resulting in a change in the crest factor from 1.438 to 1.714 .

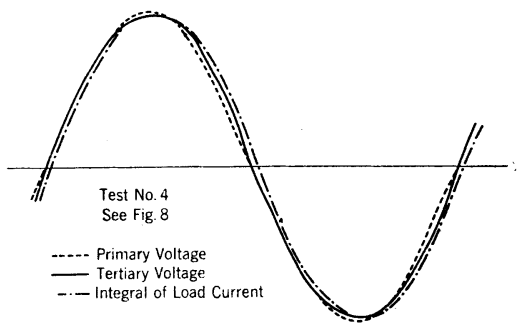

FIG. 13

The addition of load in this case therefore increased the crest factor.

There is some evidence that the tertiary voltage wave form is more likely to resemble the secondary voltage wave form than the wave form of the primary voltage. No attempt was made to determine the high-tension wave form directly, but in three of the tests this wave shape was derived by integrating the current through the condensive load expressed as a harmonic series. Dividing this integral by the capacitance of the load gave the harmonic series representing the secondary terminal voltage. Figs. 13, 14 and 15 compare the several voltage waves as mechanically synthesized from their respective harmonic series. The scale of these figures is so chosen that all the waves have the same r.m.s. value. The secondary wave shape determined in this manner is not strictly correct, on account of some corona current which was present. By inte- 
grating the whole load current and thus ignoring the in-phase component due to corona the resulting wave is made to appear to the right of the true curve; and, further, since the shift of the fundamental is proportionately greater than for the higher harmonics, the shape of the wave is affected. This error is especially noticed in Fig. 14, where the capacitance of the load was the smallest and the corona current therefore largest as compared to the condenser current. Fig. 15 shows a marked difference between the primary voltage wave and the secondary voltage wave obtained by integration, but the latter wave is in fair agreement with the wave of tertiary voltage.

These tests, few as they are, show the necessity for a knowledge of the crest factor under the particular conditions of the

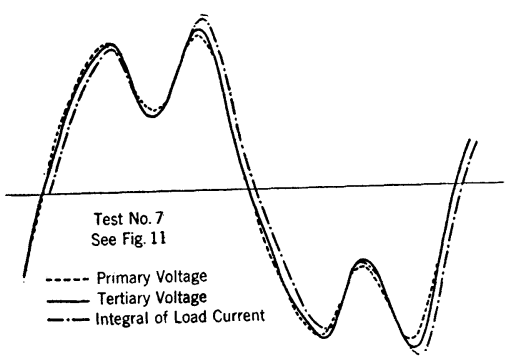

FIG. 14

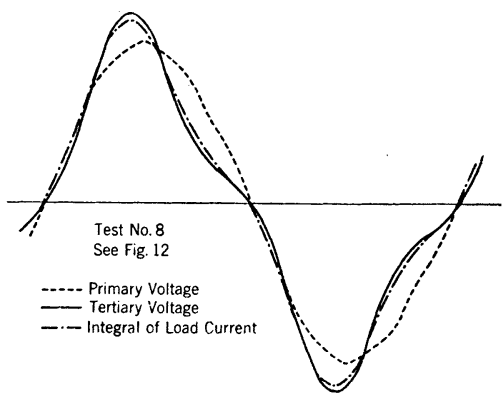

FIG. 15

test in order to use the voltage of a tertiary coil as an accurate measure of the secondary voltage.

\section{Secondary Voltage Measured by Crest Voltmeter}

Crest voltmeters having indications dependent upon the average value of the charging current taken by a condenser and thereby measuring the peak value of the voltage across the condenser have been used in experimental testing. ${ }^{4}$ In order to learn something of the usefulness of these meters under conditions prevailing in ordinary high-tension testing, a meter of this type was also used to measure the high-tension pressure in all but test 1 .

4. Calibration of the Sphere Gap Voltmeter, Chubb and Fortescue. Trans. A.I.E.E., 1913, Vol. XXXII, page 739 .

The Electric Strength of Air, Whitehead and Gorton. Trans. A.I.E.E., Vol. XXXIII, 1914, p. 951. 
For clearness the observations are here exhibited in a separate table.

TABLE II-SECONDARY PRESSURE MEASURED BY CREST VOLTMETER AND EXPRESSED AS THE R.M.S. VALUE OF THE SINE WAVE OF EQUAL PEAK

\begin{tabular}{|c|c|c|c|c|c|}
\hline Test & Supply & $\begin{array}{c}\text { Crest } \\
\text { voltmeter } \\
\text { reading }\end{array}$ & $\begin{array}{l}\text { Sec. volts } \\
\text { by gap } \\
\text { r. m. s. }\end{array}$ & $\begin{array}{c}\text { Sec. volts } \\
\text { by integ. } \\
\text { load cur. }\end{array}$ & $\begin{array}{c}\text { Error of crest } \\
\text { voltmeter } \\
\text { per cent }\end{array}$ \\
\hline & & & & & \\
2 & $A$ & 96,600 & 96,900 & & -0.3 \\
3 & $A$ & 69,600 & 69,300 & & +0.4 \\
4 & $A$ & 57,500 & 57,600 & 57,400 & -0.2 \\
5 & $B$ & 96,400 & 96,600 & & -0.2 \\
6 & $B$ & 68,300 & 67,400 & & +1.3 \\
7 & $C$ & 82,700 & 57,900 & & $+\mathbf{4 2 . 8}$ \\
8 & $C$ & 56,900 & 57,600 & 57,100 & -1.2 \\
\hline
\end{tabular}

The measurement of high voltages by this method has substantially the simplicity of the ordinary methods for low voltage, with a precision apparently limited only by the difficulties of original calibration, save in one respect. Meters of this type, employing rectifying bulbs, are inherently incapable of giving indications proportional to the highest peak of a voltage wave which has several peaks in a half-cycle. With waves of this kind the current through the condenser will have both positive and negative lobes in a half-cycle. Now the crest value of the voltage is proportional to the maximum quantity of electricity in the condenser, and this quantity is proportional to the net area of the current-time curve for one half-cycle, negative lobes counting as negative areas. The permanent magnet type instrument in series with a rectifying bulb indicates the average positive current throughout a whole cycle and thus measures the sum of the areas of all the positive lobes of the currenttime curve in a whole cycle, failing to subtract the areas of the negative lobes when these are present in the first half-cycle and adding the areas of the same lobes when they appear on the positive side in the second half-cycle. The error is therefore a double one, both elements causing the meter to measure a current greater than the true average current and therefore to indicate a voltage greater than the true high-tension voltage. Test 7 (Fig. 11) shows a case in which an extreme effect of this kind was purposely obtained by resorting to the use of Supply C. Distortions of this degree are difficult to produce and are not likely to occur in practise. 
An error of another kind will be introduced in the measurement unless the frequency of the e.m.f. being measured is the same as the frequency employed in the original calibration of the meter. Since with a constant e.m.f. the meter reading will vary directly as the frequency, the proper correction can be easily applied.

TABLE III-SECONDARY VOLTAGE DERIVED FROM PRIMARY VOLTAGE

(The secondary pressure expressed as the r. m.s. value of the sine wave of equal peak is assumed equal to r. m. s. value of primary pressure multiplied by the ratio of its crest factor to $\sqrt{2}$ and by the ratio of turns.)

\begin{tabular}{|c|c|c|c|c|c|c|c|c|}
\hline Test. & 1 & 2 & 3 & 4 & 5 & 6 & 7 & 8 \\
\hline Supply. . & $A$ & $A$ & $A$ & $A$ & $B$ & $B$ & $C$ & $C$ \\
\hline Sec. currents (amps. $\ldots \ldots$ & 0.024 & 0.035 & 0.114 & 0.342 & 0.031 & 0.110 & 0.0306 & 0.323 \\
\hline $\begin{array}{l}\text { Primary r. m. s. volts }=E_{1} \ldots \\
\text { Pri. voltage crest factor } \div \sqrt{2}\end{array}$ & 238.4 & 228.5 & 160.0 & 247.9 & 205.4 & 146.6 & 265.7 & 198.5 \\
\hline$=F_{1} \ldots \ldots \ldots \ldots \ldots$ & 1.005 & 1.014 & 1.007 & 1.000 & 1.118 & 1.042 & 0.989 & 1.016 \\
\hline Ratio of turns $=K \ldots \ldots \ldots$ & 417 & 417 & 417 & 208 & 417 & 417 & 208 & 208 \\
\hline $\begin{array}{c}\text { Calculated sec. volts }=E_{1} F_{1} \\
K \ldots \ldots \ldots \ldots \ldots \ldots\end{array}$ & 99,900 & 96,600 & 68,700 & 51,700 & 95,700 & 63,700 & $54, \% 00$ & 42.000 \\
\hline Sec. volts by gap, r. m. s. . & 103700 & 96,900 & 69,300 & 57,600 & 96,600 & 67,400 & 57,900 & 57,600 \\
\hline Per cent error............ & -3.7 & -0.3 & -0.9 & -10.2 & -0.9 & -5.5 & -5.5 & -27.1 \\
\hline Figures $\ldots \ldots \ldots \ldots \ldots \ldots$ & 5 & 61 & 7 & 8,13 & 9 & 10 & 11,14 & 12,15 \\
\hline
\end{tabular}

As would be expected, the primary voltage, even when corrected for crest factor, is not, in general, a satisfactory measure of the secondary voltage, largely because the wave form of the primary voltage may or may not resemble the wave form of the secondary voltage under given circuit conditions, the difference being especially noticeable in Fig. 15. Of course the use of the simple ratio of turns is responsible for part of the error, because the internal resistance and reactance drops in the transformer are thereby neglected.

\section{Conclusions}

For the conditions of test and with the apparatus used, the following conclusions may be drawn:

It is possible to wind in a high-tension transformer a tertiary (or voltmeter) coil in such a manner that the voltage induced in this tertiary coil, when corrected for crest factor, is a satisfactory measure of the secondary terminal pressure.

A crest voltmeter provides a convenient and, in general, an accurate means for measuring high voltages, though errors can be introduced by the use of extremely distorted voltage waves.

The primary voltage, even when corrected for crest factor, is an uncertain measure of the secondary voltage because the respective wave forms may differ. 
Discussion on "Crest Voltmeters" (Sharp and Doyle), "The Crest Voltmeter" (Chubb), “The Voltmeter Coll in Testing Transformers" (Hendricks), “ Notes on the Measurement of High Voltage" (Work), New YoRk, FEb. 8, 1916.

E. E. F. Creighton: The question of the measurement of high frequency is always important, and always will be important until all the problems relative to the protection of apparatus are solved. Dr. Sharp's statement that the kenotron might be used for the measurement of high frequency is of the greatest importance. The dielectric spark lag of a perfect vacuum is practically infinite, because there are no ions present. Going down to a vacuum of something like fifteen millimeters in the usual gases the dielectric spark lag decreases to about the low value at atmospheric pressure.

It would be of interest to know in these cases how high frequencies were used in the kenotron. I had a feeling that there was not sufficient ionization in the tube to reduce the dielectric spark lag to a value which might give direct indication of the voltage. If the dielectric spark lag is not great, or if it can be taken care of at high enough ionization with the filament, there should result another instrument for measuring transitory waves in transmission lines. These waves are very difficult to get at.

At the present time we have to depend upon a number of sphere gaps connected in parallel, each one set to a different voltage. For example, in the measurement of a 13,000-volt circuit we naturally begin with the sphere gap set on double potential. and go on from that to $2.5,3,3.5$, 4 , etc. In series with each one of these sphere gaps is placed a recording device, usually operating on the principle of the Branly coherer. If, however, the kenotron can be used for these high frequencies, and high potentials, it will give a simpler method of measuring and recording these transitory voltages.

F. W. Peek, Jr.: I have used one or the other of these methods in measuring high voltages at the ordinary frequencies of power transmission, high-voltage direct current, transient voltages of the duration in some cases, of a few millionths of a second, and continuous high-frequency voltages. The voltage range in these measurements was from zero to almost a million volts. I shall review the various methods and state their possibilities and limitations as I have found them in my experience.

For the purpose of discussion, the methods of measuring high voltages may be divided into three classes, (1) the spark gap; (2) the crest voltmeter consisting of a condenser and a rectifier in combination with frequency meters, ammeters, or static voltmeters connected directly to the high-voltage line; (3) the voltmeter coil, on the high-voltage side of the transformer, in combination with a low-voltage crest voltmeter. 
In discussing (1), the spark gap, it is only necessary to consider the sphere. With this form of gap there is no humidity correction to make. The correction for air density is readily made. The sphere gap will measure correctly the crest voltage of the most distorted wave; it will measure correctly, direct current, high frequency over a considerable range, and impulse and transient voltages of a few micro-seconds duration. ${ }^{1}$ In many high-voltage measurements the sphere gap is very desirable, in fact, necessary, to detect oscillations. It is invaluable in the laboratory in investigating transient voltages. The disadvantage of the sphere gap is that it must be set.

Under (2), two forms of crest voltmeters connected directly to the line have been described. In the method described by $\mathrm{Mr}$. Chubb unidirectional voltage is applied to a condenser by means of a rectifier. The current and frequency are read. Good results may be obtained if the wave shape is not much distorted. Errors will result if there is insulation or corona loss in the condenser as this loss current will be read on the meter. If the voltage wave has a double peak, or a sharp peak, large errors will result. This is shown in the paper by Mr. Work where a wave of the type Fig. 14 causes an error of over 40 per cent. This is a much larger error than would have resulted if no attempt had been made at correction. In the method described by Messrs. Sharp and Doyle the rectified voltage wave is applied to a condenser. The condenser is thus charged up to the maximum of the wave. The condenser voltage is read by a static voltmeter. I have used this method directly on the line for voltages of over $100 \mathrm{kv}$. I believe it to be the more practicable of these two methods. Good results may be obtained if the insulation is very good and the condenser is of fairly high capacity. If leakage occurs the voltage reading will be too low. Thus, for high voltages, the condensers become excessively large. More will be said of the application of this method at low voltages, later. Both of these methods have extensive use in the laboratory and may be of use in some practical work. Neither will measure transients or detect oscillations.

The voltmeter coil, method (3), consists of taps brought out from a few turns of the high-voltage winding of the transformer, generally at the neutral point where the voltage above ground is zero. I have for years used a transformer, designed by Mr. Hendricks, equipped with such a coil. I have made hundreds of check tests with voltmeter coils and find that when the transformer is properly designed, and the coil properly placed, the voltage and the wave measured from the coil check very closely with the voltage and wave shape across the high-side winding. The voltmeter coil requires practically no extra equipment and involves practically no extra cost. The effective voltage may be read by a standard voltmeter, the maximum may be read by a

1. F. W. Peek, Jr., "The Effect of Transient Voltages on Dielectrics." Trans. A. I. E. E., Vol. XXXIV, 1915, p. 1857. 
low-voltage crest voltmeter. This crest voltmeter may be of the type described by Messrs. Sharp and Doyle and need not be large and expensive as in the case of the high-voltage types. An oscillogram of the voltage wave may be taken at any time. The voltmeter coil with crest voltmeter seems to be decidedly the best and most convenient method of measuring high voltages in practical testing where continuous readings are desired. This should always be supplemented by a sphere gap set slightly above the applied voltage to detect oscillations, etc.

The methods of measuring high voltages may be summarized as follows:

(1) The sphere gap will measure correctly practically any form of voltage. It is the only method, at present, of measuring certain high-frequency and transient voltages. It is invaluable in the laboratory and in much commercial work, especially where transients are likely to occur.

Its disadvantage is that it does not read continuously. This is not always a disadvantage as the transformer may be calibrated.

(2) The various crest voltmeters consisting of condensers, rectifiers, voltmeters, ammeters, and frequency meters, connected directly to the high side of the line are useful over a limited range in practical work, but become troublesome, liable to error, and expensive at high voltage. They are not always accurate with distorted waves.

(3) The voltmeter coil in connection with a low-voltage crest voltmeter involves practically no extra space or expense and gives good results. The voltmeter coil with crest voltmeter and supplemented by a sphere gap to detect oscillations offers the best arrangement for general commercial testing.

F. M. Farmer: The problem of measuring high voltages usually involves two things, the mean effective value and the maximum value.

The first method used for measuring high voltages employs the low-tension voltage and the ratio of transformation. This method is deficient, in that we do not know anything about the ratio under varying load conditions nor have we any knowledge of the crest factor.

The next scheme developed was the use of electrostatic voltmeters on the high-voltage circuit. That gets rid of the ratio difficulties and gives us a mean effective value, but the scheme has voltage limitations because of construction difficulties at very high voltage and also because stray electrostatic field troubles become serious. Furthermore it does not give the crest voltage.

The test coil seems to be the proper thing for measuring mean effective values on the high-voltage side, but there again, some investigation is necessary to be sure of the ratio of the test-coil voltage to the total voltage under various load conditions and various dispositions of the sections of the secondary winding. Of course, in our very high-voltage testing, it is not customary to 
divide the high-tension winding, but in the ordinary testing transformer for routine testing at moderate voltages, the secondary winding is split up into two, four, or even eight sections, so as to be able to get the maximum kilovolt-ampere capacity of the transformer at all voltages.

The best arrangement, therefore, seems to be the use of a test coil in the high-tension winding of the transformer. An ordinary voltmeter gives the mean effective value and a crest voltmeter gives us the maximum value.

There is one question I would like to ask Mr. Chubb. Is there any variation in the capacitance of the condenser bushing? At the very high voltages is it possible that that capacity will change and thus introduce an error. In other words, does the capacity remain constant at all voltages?

Frederick Bedell: One feature of the crest voltmeters described in these papers is that it is possible by means of them to obtain an instrument reading of crest voltage without the use of a synchronous contactor. Another method for obtaining such readings without the use of any synchronous device is the method described $^{2}$ by Professor Ryan in which an impulse transformer is employed, in place of a synchronous contactor, in conjunction with the Duncan method for obtaining a-c. wave form. The impulse-transformer method makes unnecessary the synchronous contactor, but it does require the locating of the maximum reading by trial, so that readings of crest voltage are not made directly as by the crest voltmeters we have just heard described.

Comfort A. Adams: I agree thoroughly with Mr. Hendricks that it is unnecessary to go to great lengths in the measurement of peak voltage, provided you have a suitable alternator and transformer and can depend upon the voltage wave shape impressed upon the transformer, in which case an ordinary voltmeter connected to a suitably placed voltmeter coil in the transformer, will give fairly accurate results. Moreover, such an equipment is desirable not only because it facilitates voltage measurement, but also because harmonics in the e.m.f. wave are undesirable on at least two other accounts. They produce undue heating of the dielectric in some cases, and also tend to encourage transients of still higher frequencies.

We have much to learn on this subject of insulation and cable testing. In high-voltage testing very high-frequency transients of excess voltage do occur, of this there is ample evidence, and until they are under control or brought within the realm of measurement, it behooves us to go slowly. As yet the spark gap in some form is the only simple detector of transients, but even if it could be conveniently arranged for measurement rather than for detection, it would still be dangerous because of its habit of producing the very kind of a disturbance it is employed to detect. Some materials withstand abnormal transients without rupture, provided they are not repeated too often, while

2. Transactions, Vol. XVI, p. 345, 1899. 
more fluid materials will fail and heal up many times before final rupture.

W. I. Middleton: It is very apparent from the papers that have been presented here today that the importance of a knowledge of the maximum voltage in connection with high-voltage testing is being appreciated more and more. It is not so much a question of whether the wave is distorted or not, but as to how much, and until generators giving a sine wave under a testing load are more commonly used than at present, it should be the desire of all interested to develop an instrument or instruments, that will give a direct reading in volts of the pressure at the peak, or crest, of the voltage wave.

In the early part of 1900 all of our investigations in high-voltage testing were done with the spark gap, and by its constant use under every condition of test that would arise, we were convinced that it was impossible to tell accurately what was the maximum voltage being applied to a cable under test.

In the latter part of 1911 , while investigating the variations in the voltage waves of our testing set with an oscillograph, Mr. Dawes and I decided that as it was the peak of the wave we were interested in rather than its shape, an instrument much simpler than the oscillograph could be made, and in April, 1912, a working model of our instrument was being used in our factory.

The authors show some badly distorted waves obtained under testing conditions: We have experienced considerable difficulty from just such waves.

Fig. 1 shows a voltage wave obtained from a single-phase generator when it was supplying power to a step-up transformer, to the secondary of which was connected a cable undergoing test. The voltage wave is not unlike some of those shown in the papers. The current wave crosses the zero axis three times in a half cycle; its third harmonic has a greater amplitude than its fundamental. We have found the peak voltmeter very useful in checking such waves.

The instrument which we are using is based on the oscillograph principle, and therefore takes a very appreciable current, so we cannot use a condenser train as a multiplier without going to considerable trouble and expense. Therefore, we are obliged to use an instrument transformer to step down the voltage.

There has been raised some question regarding wave distortion taking place through a potential transformer. We have checked peak factors at various times with our peak voltmeter, but have never been able to detect any difference between those on the primary of the step-up transformer and those at the secondary of the potential transformer. As further, evidence, we have taken oscillograms of such waves.

In Fig. 2, the wave marked $G E$ is the voltage wave of a special sine-wave alternator. As we have never been able to apply a load that would produce any appreciable change in the shape of this wave, we introduced an air-core choke-coil into the line in 
series with the primary of the step-up transformer. Due to the non-sinusoidal drop through this choke-coil, the voltage at the transformer terminals had the form shown by the Wave $T_{1}$. The wave $T_{2}$ was taken simultaneously on the secondary of the potential transformer. The oscillograph vibrators were connected so that both waves were on the same side of the zero axis, and the multipliers were so adjusted that each voltage wave had the same amplitude. It will be seen that there is no appreciable difference in the shape of the two waves. There is, of course, a slight shifting of phase through the two transformers. Any variation of the voltage wave form is due to the fact that the current produces $I R$ and $I X$ drops in the transformer windings, which differ considerably in wave form from that of the applied potential wave. Also these waves were taken at only 13,000 volts. I realize that, at the higher voltages, distortion may occur due to capacity effects in the transformer windings.

If Dr. Sharp has developed an instrument that will trap and hold transient voltage peaks so that their value may be determined, I am sure that it will be found very useful in connection with high-voltage testing, especially in cable testing, where there is a large amount of capacity in the circuit. We have evidence that surges occur very frequently when the cable is long and the voltage is high. I am certain that many cables have punctured at voltages much higher than have been shown on the indicating instruments, due to surges occurring in the circuit. The presence of these transient peaks may be wholly unknown to the person making the test, unless he has some such instrument as Dr. Sharp describes.

J. R. Craighead: I made a few experiments and got some data in connection with the use of the kenotron with the electrostatic voltmeter on high-tension circuits at 60 cycles. In order to get the matter down to a point where a comparison could be made with the oscillograph with series resistance, voltages were used, not of the order being talked about this afternoon, but with the maximum limited to 7000 volts. The oscillograph was used photographically each time, and measurements made as carefully as possible in order to determine the correspondence between the electrostatic and the oscillograph. The electrostatic itself was calibrated on a sine wave after each successive trial, in order to be sure that the instrument itself did not change. Three waves were used, the crest factors varying from 1.405 , which was practically a sine wave, up to 1.56 . One of the three waves, the one whose crest factor was 1.56 had three peaks between each pair of zeros, although two of the peaks were very small.

The results, of which I have made a tabulation, show that the maximum difference within six successive trials taken of the three waves, between the crest voltmeter and the oscillograph, was about 0.2 of 1 per cent. The maximum difference on any trial was about 1.2 per cent, which was practically as close as a standard electrostatic voltmeter of 10,000 volts could be used 
PLATE $V$.

A. I. E. E.

VOL. $X>X V, 1916$

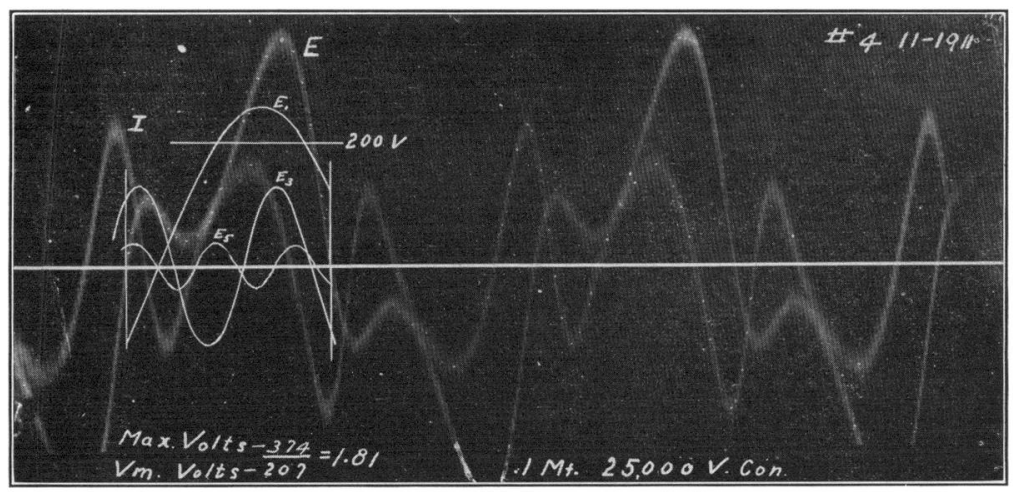

FIG. 1

[MIDDLETON]

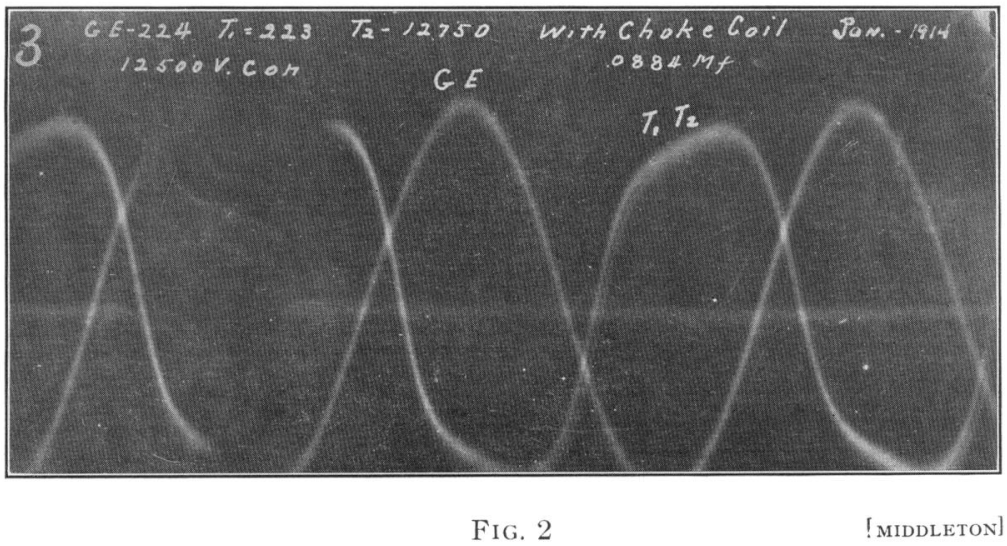


at that point. All of the trials came within considerably less than 1.2 per cent, which represented the outside of the six.

In respect to the rectifier that was used, there is a characteristic of most rectifiers that causes them to have a rather definite voltage drop which is not altogether dependent on the current nor proportional to the current. In order to show as much of this drop as possible a kenotron was used which was capable of standing about 70,000 volts maximum, at about 10 per cent of the voltage it was expected to stand.

In respect to the capacity which was necessary in order to keep the voltmeter at a correct maximum reading, a very much smaller value than Dr. Sharp has suggested was found quite satisfactory. For the most part, these tests were made with 0.002 of a microfarad in multiple with the voltmeter itself.

The table to which I refer is as follows:

\begin{tabular}{|c|c|c|c|c|c|c|}
\hline \multirow{2}{*}{$\begin{array}{l}\text { No. } \\
\text { of } \\
\text { test }\end{array}$} & \multirow{2}{*}{$\begin{array}{l}\text { Average } \\
\text { crest } \\
\text { factor }\end{array}$} & \multicolumn{2}{|c|}{$\begin{array}{l}\text { Average of maximum } \\
\text { readings }\end{array}$} & \multicolumn{3}{|c|}{$\begin{array}{l}\text { Per cent variation of electrostatic volt- } \\
\text { meter with Kenotion from oscillograph }\end{array}$} \\
\hline & & $\left|\begin{array}{c}\text { Oscillograph } \\
\text { through } \\
\text { resistance }\end{array}\right|$ & $\begin{array}{l}\text { E1. volt- } \\
\text { meter with } \\
\text { kenotron }\end{array}$ & $\begin{array}{l}\text { Maximum } \\
\text { positive }\end{array}$ & $\begin{array}{l}\text { Maximum } \\
\text { negative }\end{array}$ & Average \\
\hline $1-2$ & 1.405 & 7186 & 7175 & +0.7 & -1.0 & -0.2 \\
\hline $3-4$ & 1.485 & 7126 & 7185 & +1.2 & $\ldots$ & +0.8 \\
\hline $5-6$ & 1.56 & 7165 & 7165 & +0.5 & -0.4 & 0 \\
\hline
\end{tabular}

I ask Dr. Sharp if his tests were all made, as shown on the diagram, on ungrounded circuits or whether he used grounded circuits in any instance, and at what voltages the tests were made.

C. L. Dawes: There is still another type of crest voltmeter which has not been mentioned. We have found the oscillograph type of crest voltmeter very useful in connection with cable testing, but there are certain conditions under which it cannot be used to advantage because of the very appreciable current which it requires for its operation. This has led me to develop an electrostatic type of meter. The principle of the instrument is not original, but was suggested to Prof. A. A. Laws and myself by a paper written by E. T. Jones, appearing in the Philosophical Magazine ${ }^{3}$ some time ago. However, the instrument there described was wholly unsuited for high-voltage testing, and therefore it was necessary to modify the design very materially.

Fig. 3 shows the general scheme of the voltmeter. For the sake of clearness, no attempt has been made to show the parts in their correct proportion. A phosphor-bronze filament is

3" A Short Period Electrometer and Its Use in Determining the Frequencies of Slow Electrical Oscillations."' Philosophical Magazine, 1907, p. 238 . 
stretched between two points of support $A A$, the proper tension being secured by the spring $B$. This filament is held to the spring by a short length of silk thread for insulating reasons. Beside and close to this filament a small silk thread $C$ is stretched, being drawn as tightly as its tensile strength will permit. Across the filament and thread, midway between the supports $A$, a small mirror $D$ is cemented.

In front of the filament and very close to it, a brass plate $E$ is fastened. Through the center of $E$, there is a small hole just large enough to allow a beam of light to enter and leave. The filament and this plate are connected together to form one terminal of the instrument. The other terminal of the instrument is the small brass plate $F$, secured to the hard rubber barrier.

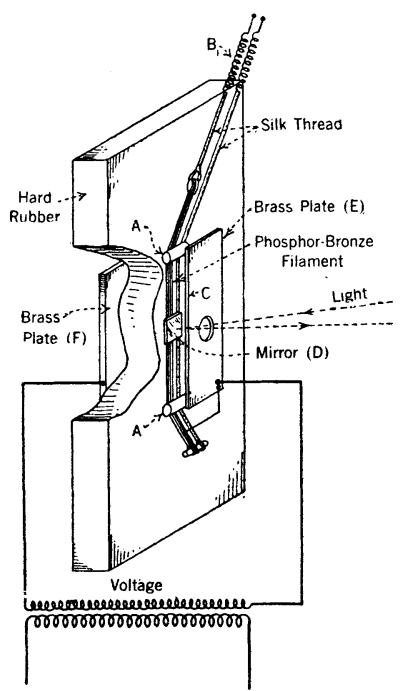

FIG. 3

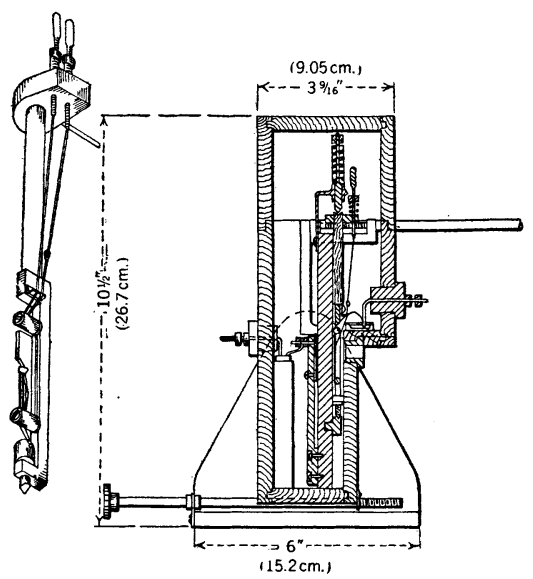

FIGS. 4 AND 5

This barrier acts as a dielectric to prevent breakdown between the terminals.

When the brass plate $E$ and the filament are both positive, there is electrostatic repulsion between them because like charges exist on both. On the other hand, there is attraction between the plate $F$, which now has a negative charge, and the filament. As the silk thread is not influenced by the electrostatic charges, it remains practically stationary, serving only as a hinge about which the mirror swings. Therefore, the left hand side of the mirror will be drawn toward the barrier. When the polarity is reversed, the mirror will still deflect the same way, because the charges on plate $E$ and the filament are always the same and those on plate $F$ and the filament are always opposite. Therefore, the mirror deflections are proportional to the square of the voltage and the deflection is always in the same direction. The 
deflection of the mirror is read by noting the breadth of a band of light upon a scale. Fig. 4 shows the vibrator which is removable from the barrier.

The instrument does not operate satisfactorily in air, due to corona and brush discharge from the filament, therefore it is necessary to immerse it in oil. Fig. 5 shows a cross-section of the instrument immersed in a box containing white oil. Connections to the plate are made through mercury cups, which connect to binding posts through hard rubber bushings.

It will be appreciated that this instrument has so little electrostatic capacity that it is almost negligible. Therefore, it is very easy to use it in connection with a condenser-train multiplier having a very small capacity. Also the instrument may be used to measure induced potentials upon insulated bodies whose capacity to the system is so small that the voltage would be disturbed by even the small capacity of other types of electrostatic instruments. For instance, Mr. Middleton and I have frequently used the instrument to measure induced charges on cable sheaths and on insulated conductors having high-potential wires in their neighborhood. This instrument does not need to be grounded, but may operate at potentials far above that of the ground. For instance, we have used it to measure a potential of 30,000 volts when one terminal was at 30,000 volts and the other at 60,000 volts above ground potential. Up to the present we have calibrated the instrument by connecting it to the secondary of a step-up transformer which is delivering no load. Under these conditions, we know the voltage wave to be essentially sinusoidal. The instrument at present can be used safely up to 30,000 volts, but there is no apparent reason why it cannot be designed to operate at much higher potentials than this, provided that appreciable corona discharge from the filament to the oil is not allowed to occur.

This voltmeter is independent of wave form and negative loops; although it cannot register surges, it has been able to indicate the apparent peak of surges in the circuit to which it was connected.

John B. Whitehead: All three of these papers describe the use of the electric valve for measuring the maximum value of voltage. Reference is made to the work of Dr. Gordon and myself in which we measured corona voltages at frequencies higher than sixty cycles. We used the mercury electric valve for obtaining maximum values of voltage at the higher frequencies, in much the same way as now described in these papers.

I mention this in order to answer Mr. Creighton's question as to the frequency at which the valves may be used. At that time we were working up to 3000 cycles. From the nature of the kenotron, I see no reason why it should not be available for far higher frequencies than this.

I wish to describe some experiments we have been making with still another type of crest voltmeter, namely, the corona voltmeter. 
It has been frequently brought to the attention of the Institute that the value of the voltage at which the corona comes out on clean wires is extremely sharply marked. Suitable corrections, which are now perfectly well understood for temperature and pressure, may be made. It is quite possible to read and re-read corona voltages on clean wires to a far higher degree of accuracy than the constancy of the usual circuit, even in a laboratory, where precautions to secure constancy are taken.

Within the last two years I have been trying to use the principle of the breaking out of corona on the peak of the voltage wave as a basis for direct observation of crest voltages. The great difficulty in using the corona, a difficulty which is at once obvious, is that it is directly dependent upon the size of the wire, and that consequently for any range of scale in such an instrument the size of the wire would have to be changed. There is another difficulty, namely, that some method of detecting the beginning of corona, other than by direct visual observation must be devised.

I have met the first difficulty very satisfactorily, so far, by enclosing the whole corona tube, with its central wire, in a larger outside tube, varying the pressure in this outer tube and, reading the pressure and the temperature in order to apply the correction. The instrument can then be set for any voltage by varying the pressure in the outer containing cylinder, or, if it is desired to measure an unknown voltage, it is simply a matter of lowering the pressure until corona appears. In other words the range of the instrument will be taken care of by running the pressure either up or down in the outer containing tube.

For the observation of the beginning or presence of corona, we have developed three very satisfactory methods. The first is that which uses the gold-leaf electroscope in connection with a small electrode outside of the cylinder forming one side of the voltage terminal, as described in my papers, the Electric Strength of $\mathrm{Air}$. This electrode is placed directly opposite a few small holes in this cylinder and the ionization that comes from these holes is quite sufficient to discharge even a crude and rugged type of electroscope.

The second method is by the use of the galvanometer in connection with d-c. voltage. In order to use this method, the electrode is increased in size, so as to form still a third outside cylinder very close to the main cylinder forming one side of the high-voltage circuit, the latter cylinder being perforated with many holes over its whole circumference so as to provide a very large aggregate opening for ionization. With d-c. voltage on the enlarged electrode and a galvanometer in series, the beginning of corona is marked by a sudden deflection.

Still a third method which has been surprisingly satisfactory is the use of the telephone. We enclose a telephone transmitter inside of the pressure cylinder. We do not normally think of a frequency of 60 cycles as one which would give any appreciable 
note with a telephone transmitter. There is, however, something other than the normal 60 -cycle note in the high voltage corona and it is these higher spark tones which the telephone seems to pick out. The beginning of corona is attended by a sharp sound in a receiver connected to the transmitter located as described. We are now using all three of these methods of observation and they show a most gratifying agreement.

We can add a fourth method, if we will, the visual corona, always a very satisfactory means of observing the maximum point, but not suitable for an instrument for use in the open, as in a manufacturing shop, or power station. The eyes must be rested in the dark at least five or ten minutes before visual corona can be observed satisfactorily.

L. W. Chubb: In the paper by Sharp and Doyle the authors speak of leakage demanding a certain amount of capacitance in parallel to the meter. The dielectric resistance of electrostatic voltmeters is usually very much higher than any condenser, unless it be of the air type. Also, the rectifier resistance is higher in the reverse direction than that of the condenser, so that if more condensance is put in parallel we should expect more rapid discharge in spite of having more power stored.

Very likely the leakage between peaks is due to corona.

One of the speakers stated that he used less condensance when working at 7000 volts. Is it not likely that this was possible because the voltage was below the corona point and leakage was low.

Dr. Sharp speaks of registering the magnitude of surges with such an instrument, but I believe he will only reach a middle ground in obtaining a surge. The authors state in the paper that "if it does not build up on the first cycle it will on succeeding cycles." Sometimes the surges which come along are very steep, high frequency, and very quickly damped, so that if the first impulse is not enough to charge the electrostatic voltmeter and condenser, the following impulses will not be enough to raise the charge to the voltage of the first impulse.

The current through the condenser at the instant of a surge should be of the order of amperes instead of milliamperes. The kenotron current is limited by space charge and by temperature of the filament, so the condenser cannot be filled on the first impulse. Also with any appreciable damping constant, the succeeding peaks of the surge will not charge the condenser to the voltage of the first peak.

The multiplier method with two or more condensers in series with the electrostatic voltmeter in parallel with one unit would not divide the voltage by ratio during the surge transient, even if there were no current limitation of the kenotron, for if the voltmeter is to store a charge there must be an equal charge displaced in the opposite direction in the series condenser because a d-c. component of current cannot flow through the series condensers. 
The ratio of series condensers has also been found to be wrong unless the several units are guarded by the principles which Mr. Fortescue presented before the Institute some time ago, and unless corona is prevented on any but the outside terminal of the end condenser.

The resistance multiplier is also open to the same objection and errors will result unless capacity to ground and between sections is eliminated by electrostatic shielding.

With the kenotron used on the high-tension side of the transformer as shown by the authors, it must be capable of standing twice the peak voltage, for on the reversed half cycle the charge of the condenser and the transformer voltage are in series adding. It therefore seems that the scheme, measuring crest voltage, would not be very simple on voltages above 100 or $200 \mathrm{kv}$.

I was very much interested in the test results given in Prof. Work's paper, and I may add I have seen very much worse distortions in testing waves which, I think, will give greater errors with a volt coil. We have tested out the voltage per turn through the secondary winding under various load conditions. In one case I remember the voltage in a secondary turn was reversed in a certain part of the leg from what it was in others. This means that if the volt coil is to be accurate it must be perfectly coupled with the secondary, or must be placed in the average position. The average position depends on the nature of the load, because there is a shift of leakage reactance between the two coils.

Our experience with the volt coil has not been very satisfactory due to improper placing and the resonance of upper harmonics between the load and the leakage reactance of the secondary. However, the results shown by Prof. Work indicate that the volt coil is quite reliable, when crest factor corrections are made.

Clayton H. Sharp: I evidently did not make it clear that these experiments were all made on low voltage, that is to say, the instrument itself, the electrostatic voltmeter, was graduated to read a maximum of 250 volts. So questions of huge condensers etc. do not apply to these experiments. The crest voltmeter as we worked it out was used on voltmeter coils, tertiary winding of the transformer, and one side of it was grounded, so that the whole thing was practically at earth potential.

There is no reason why it cannot be used on a condenser multiplier, and I do not quite see why the multiplier needs to be a whole string of condensers. It can be one high-voltage condenser, and in series with it another one of large capacity connected to earth. Thus one condenser takes the bulk of the voltage drop, and the other one, of larger capacity, takes a small portion of the voltage drop and the crest voltmeter is looped about that. Then the indications of the crest voltmeter will depend on the ratio of the two. While I cannot speak from actual experience, I do not see any reason why it should not work, and I do not see any reason why Mr. Chubb's condenser bushing could not be used as the high-voltage condenser. 
With regard to the measurement of high-frequency surges, etc., what we have in our paper is simply offered as a suggestion, and is not backed up with any very positive statements, because we have not the data or the experience on which to rest them. In our paper we say: "In conclusion, it may be noted that the arrangement given offers possibilities in the matter of the study of surges." It may do it, or it may not do it. It looks to me as if, while it is rather improbable, that the full value of the first peak of the high-frequency surge would be given, at the same time the arrangement might be of a good deal of value, even if it did not give the whole thing. Undoubtedly, with a surge there would not be the same building up effect that there is with a steady alternating-current, because the first peak is the one that counts, the oscillations being damped out rapidly after that.

It will be noted, however, that if one kenotron has not a large enough saturation current to catch the surges perhaps two or three or more in parallel may have.

When commercial instruments are available by which the crest values of waves can be measured as readily as the effective values now are, we shall avoid a lot of trouble, escape a lot of mysterious things which occur in high-voltage testing and increase the accuracy and the worth of such work.

C. F. Harding: One very important feature of high-voltage measurement which has not been touched upon in the foregoing papers is the establishment of a more satisfactory primary standard than the combined needle and sphere spark gaps. That these are not entirely satisfactory is freely admitted, for they are subject to correction for barometric changes and in practise it is found very difficult to make the two standards coincide within the range between $30 \mathrm{kv}$. and $50 \mathrm{kv}$. where both are standard. Tests covering a large voltage range such as is required upon a line of pin type insulators or upon varying numbers of suspension units in a string are difficult to make when a double standard involving variable and uncontrollable factors is used.

Whereas the meters described in these papers are designed and intended for intermediate or secondary standard use and must be referred to the needle and sphere gaps for calibration, it may be of interest to reconsider the principle of the electrostatic field with a view toward its use as a high-voltage standard.

If, for example, a uniform electrostatic field can be maintained at the center of two horizontal circular metal plates of a relatively great diameter as compared with their distance apart, and if a small circular disc be cut from the center of the lower plate and supported upon a float just below the plane of the lower plate in a tank of liquid, the force required to raise this disc to the level of the lower plate can be readily calculated in terms of the voltage impressed between the plates. With the plates near together this voltage may be small and therefore accurately determined by other means than the spark gap. If 
the field is maintained uniform by applying higher voltages between the plates as they are separated from one another, the force necessary to hold the movable disc in the plane of the lower plate will be constant and the voltage will be directly proportional to the distance between plates.

Such an electrostatic voltmeter has been constructed at Purdue University by Messrs. B. S. Wright and H. R. Holman under the direction of the writer, and readings at low voltages confirm the theoretical straight line relation between voltage and distance between plates. This line extended may be used within the limits in which no corona forms for a standard of voltage, the particular instrument constructed having a range of $180 \mathrm{kv}$.

It should be noted that such a meter would indicate effective volts and that the crest voltage would be determined only after the wave form was known. However, since the crest voltmeters are equally restricted in determining effective voltages and since the latter values at high potentials are becoming of more importance as the losses in dielectrics are being studied quite as much as break-down voltages, further steps are being made to perfect the details of this instrument with the hope that it may be seriously considered in the future as a standard for high-voltage measurement.

W. D. Peaslee: Referring to Fig. 1 of Mr. Chubb's paper it must be recognized that the arrangement as shown will give satisfactory indications only on steadily maintained voltage conditions, as the instrument intrinsically gives a deflection that is some function of the entire wave or series of waves and will indicate an entirely unknown function on a portion of a surge which lasts in terms of cycles rather than seconds. For this reason the indication of the instrument is a measure of maximum voltage only when it is calibrated and used on a particular wave form. What is needed is an instrument that will indicate the maximum voltage applied regardless of wave form and even when this maximum is a combination of a normal frequency (60-cycle) voltage and a superposed high-frequency wave or transient.

It has been shown ${ }^{4}$ that the voltage stress imposed on a system by the combination of audio and radio-frequency voltages is substantially the sum of the individual stresses imposed by the individual voltages.

It is therefor necessary in high-voltage testing that an instrument be developed that will indicate at the moment of failure, the actual maximum stress on the medium under test whether consisting of a steady 60 -cycle voltage, a transient or a combination of the two. The sphere gap, as has been shown by Prof. Ryan and Mr. Peek gives a fairly reliable measure of the stress resulting from any of these combinations but it is in difficulty of

4. Sustained Radio Frequency High-Voltage Discharges" by Harris J. Ryan and Roland G. Marx, Proceedings of the Institute of Radio Engineers, presented Sept. 16th, 1915 at San Francisco. 
manipulation that this device fails in most cases rather than in a failure to give on break-down an accurate indication of the maximum stress, as intimated by the author.

The only device that seems at present to show distinct promise in this line is the cathode-ray cyclograph which, when properly handled will meet to a remarkable degree the requirements mentioned. The indications of this instrument are of maximum values and the calibration is easy. The duration of a surge measurable by it is dependent on the ability of the eye to catch the lengthening of the voltage line and it is hoped to develop a means whereby the eye may be replaced by an electric or chemical device and thus greatly shorten this interval.

As an indication of the extent to which this superposition of normal and high-frequency voltages may affect the results indicated by an instrument of the type described by the author we have found it possible, in the high-tension laboratory to subject an insulator to a stress just under flashover at 60 cycles and hold this stress on it indefinitely without puncturing the insulator. However, when besides this voltage at normal frequency we subject the insulator to a high-frequency stress consisting of several trains of damped high-frequency waves resulting from an arcing ground on the artificial line to which the insulator is connected it will be punctured with a very few applications, if the high-frequency stress is great enough. The instrument described in Mr. Chubb's paper will not give a reading that is a known function of the actual stress that punctured the insulator, but would indicate a lower maximum voltage than that under which the insulator actually failed.

Also the error mentioned in the discussion of Fig. 5 in the paper is a double one as the meter will not only integrate all the positive current areas and neglect the negative ones but will in the next half cycle, which should be entirely eliminated, integrate these negative areas. Thus the meter will read high by twice these negative areas. It will also be in serious error when applied to a wave consisting of a normal frequency wave with the superposition of high-frequency trains or surges.

Referring now to the paper by Messrs. Sharp and Doyle it is very probable that the charge will require several succeeding half waves. Also the fact that the instrument will not recede from it's maximum reading for an appreciable time after the application of the maximum, this time depending on the leakage of the equipment, may introduce serious errors in determinations made with this instrument. Suppose a test is required of 60,000 volts for one minute and that on bringing the voltage up the first few cycles, enough to complete the charge, this voltage was 60,000 but that it then dropped to 50,000 volts. The instrument, until leakage had permitted it to drop back to the lower voltage, would indicate that the required voltage was applied to the insulator while in reality it was subjected to 60,000 volts for a few cycles only and for the rest of the minute to only 50,000 volts. This might result in the acceptance of defective material. 
This effect will be more serious the quicker the charge is built up and the less the leakage.

Also the use of the instrument as a surge trap is open to question until it is shown that the charge is built up in the time of the surge duration.

While these two papers are very valuable additions to the field of high-voltage testing and investigation, it would hardly seem that there was sufficient proof of the value and reliability of either method to accord them a place in the Standardization Rules at present, because of their inherent limits and also because it is quite probable that the cathode ray tube will be developed into a practical form for measuring these maximum values of voltage, both of normal frequency and transient wave trains, and of the two combined. As at present available it is much more satisfactory as a maximum-voltage measuring device than either of the instruments described and its failure on transients is due only to the inability of the eye to catch the record of the transient. If any change is made in the Standardization Rules the cathode ray tube should be carefully considered and given its rightful place as a means of measuring maximum-voltage values.

L. W. Chubb: Mr. Peek spoke of the errors due to corona. With the single condenser in series with the crest voltmeter there would be no error from corona, because you are measuring the voltage which is impressed upon the condenser. It does not matter how much corona there is, the line will supply all. If there are several condensers in series, the corona on and charging current of intermediate steps will cause an error except with the condenser terminal or with other similiarly guarded scheme. Each layer of the terminal is in its proper equal-potential surface, and there can be no corona, except possibly around the hat. These terminals will run to very high voltage without any corona at all, on the intermediate steps.

Mr. Peek spoke of the cost of such crest voltmeters going up as the voltage increases. I might add, with reference to the crest voltmeter described in my paper, that the cost goes down as the voltage increases. The condenser terminal is either a feature of the transformer, or it may be a roof bushing. As the voltage goes up, there is more current through the same condenser, and it takes less sensitive and cheaper instruments to measure it.

Mr. Farmer asked about the variation of capacitance of the condenser terminal. That is covered in the paper. It increased from 4 to 5 per cent from very low voltage up to 25 per cent over voltage, but this causes no error, as the crest voltmeter is calibrated in parallel with the spark gap and the variation is, taken care of in the calibration.

M. G. Newman: In the third paragraph of Mr. Hendrick's paper the statement is made: "For precise results at all loads and power factors, it is necessary and sufficient that the ratio of the flux linkages of the voltmeter coil and the high-voltage winding be a constant." . This is done by the proper design and 
placement of the voltmeter coil. I would like to explain the method of determining the accuracy with which the above condition is realized.

Referring to Fig. 6, transformer $(A)$ is the transformer with voltmeter coil under test. Transformer $(B)$ may be a potential transformer or any transformer which can be used to step-down to a secondary voltage which can be easily measured.

Voltmeter (1) is connected to the voltmeter coil of the transformer $(A)$ and voltmeter (2) is connected to the secondary of transformer $(B)$. Excitation is applied to the low voltage winding of the transformer $(A)$. First a reading is taken at no load, voltmeter (1) and voltmeter (2) being read. Various loads are applied at $(C)$ (either capacitance or inductance), the voltage and frequency being maintained constant and readings being taken on both voltmeters. The accuracy of the voltmeter coil is good if the ratio of the voltmeter (1) reading to voltmeter (2) reading remains constant from no load to full load.

We do not have to depend upon the accuracy of ratio of trans-

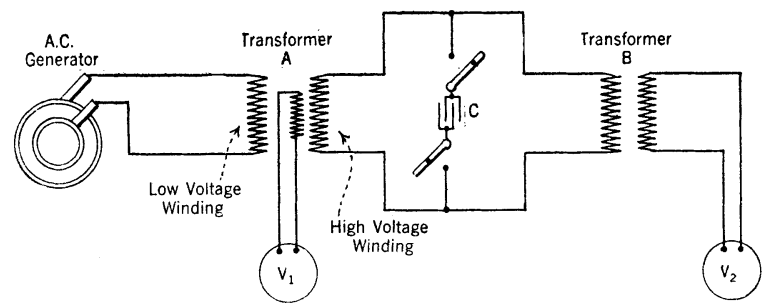

Fig. 6-Method of Testing the Accuracy of Voltmeter Coll

former $(B)$. The assumption is that the ratio of this transformer will remain constant while tests are being made.

Errors due to flux leakage between the voltmeter coil and the high-voltage coil are shown to be very small.

A full capacitance load makes a small error in one direction and an inductance load an error in the other direction but with correct design these errors can be kept well below one per cent.

A. B. Hendricks, Jr.: I heartily agree with Mr. Peek in his final conclusion that "the voltmeter coil with crest voltmeter and supplemented by a sphere gap to detect oscillations offers the best arrangement for general commercial testing."

A crest voltmeter designed on the principle recommended by Sharp and Doyle, and connected to a voltmeter coil, has been constructed by Mr. Newman, and found to be in every way most satisfactory.

As it is built for low voltages and connected direct to the voltmeter coil, all parts are small, simple and inexpensive. In practise, the indications have been found to be correct and reliable.

Of course, this gives the crest value of periodic waves only, and does not indicate single transients of short duration. 
As stated by Mr. Peek, the voltmeter coil reproduces the wave form in the high tension winding with such fidelity that there is no necessity for connecting static voltmeters or rectifiers directly in the high tension circuit, which is fortunate, since instruments designed for the extreme voltages contemplated have usually been unsatisfactory.

The method of using rectifiers, a condenser and a direct current voltmeter as described by $\mathrm{Mr}$. Chubb is more complicated and less accurate on distorted waves of certain classes than the scheme described by Sharp and Doyle. It is not correct on multiple peaked waves, and the accuracy of the indications is absolutely dependent on the frequency. Neither of these objections applies to the scheme described by Sharp and Doyle, which is in other respects much simpler also.

Of course, every precaution should be taken in designing a transformer with a voltmeter coil to insure that the indications of the latter will be correct. Apparently, in the transformer referred to by Mr. Chubb, these precautions were not observed, with results as related by him.

As it seems to be difficult to convince the average engineer that the voltmeter coil is practically exact at all loads and power factors, I give herewith the results of tests recently made on a $300-\mathrm{kw}$., 300,000-volt transformer having one end of the high-tension winding permanently grounded. See Fig. 7 .

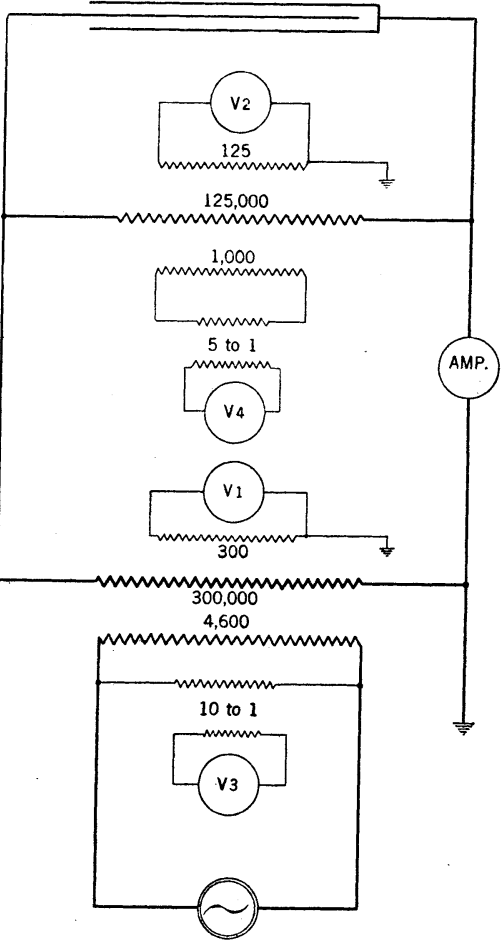

FIG. 7

The transformer was connected to a sine wave generator and the load consisted of a lead covered cable, especially made for use as a condenser.

The potential transformer consisted of another testing transformer rated $25 \mathrm{kw}$., 125,000 volts with one end of the high tension winding also permanently grounded.

With a pure condenser load it was found that the error of the voltmeter coil was too small to be detected by the best grade of portable dynamometervoltmeters, especially calibrated and interchanged, and read to $1 / 5$ of 1 per cent.

This may be considered a zero error, since it is indeterminate by the most accurate form of commercial instrument, and even the sign of the error is unknown. At the same time the error, 
reading from the low-tension winding through a potential transformer was 7.6 ,per cent or close to the measured reactance voltage of the transformer, as was expected.

Normal rating of testing transformer:

60 cycles, $300 \mathrm{kw}$., 300,000 to 4600 volts.

Voltmeter coil reads 300 at 300,000 volts.

Normal rating of main potential transformer:

60 cycles, $25 \mathrm{kw}$., 125,000 to 1000 volts.

Voltmeter coil reads 125 at 125,000 volts.

Ordinary potential transformers of 10 to 1 and 5 to 1 ratio were used on the low voltage side of the 300,000 -volt and 125,000 volt transformers.

Test was made at 60,000 volts and 0.88 amps. in the high-tension circuit, the normal rating being 300,000 volts, 1 ampere.

The absolute variation of high-tension voltage from the winding ratio depends entirely on the magnitude and phase of the current and the per cent variation at 60,000 volts is of course five times normal.

The exciting current of the 125,000 -volt transformer at 60,000 volts is so small that its effect on the power factor of the load can be neglected.

$V_{1}=$ actual reading on voltmeter coil of 300,000 -volt transformer.

$V_{2}=$ actual reading on voltmeter coil of 125,000 -volt transformer.

$V_{3}=$ actual reading on low voltage side of 300,000 -volt transformer through 10 to 1 potential transformer.

$V_{4}=$ actual reading on low voltage side of 125,000 -volt transformer through 5 to 1 potential transformer.

Amperes $=$ actual reading on ammeter in 300,000-volt circuit $=$ condenser + step down transformer currents.

The normal rated voltage of each winding is given on the diagram of connections.

The readings given are from the actual indications of each instrument after correction in accordance with the special calibration of each.

After taking one set of readings, the voltmeters were interchanged as indicated, and a second set taken.

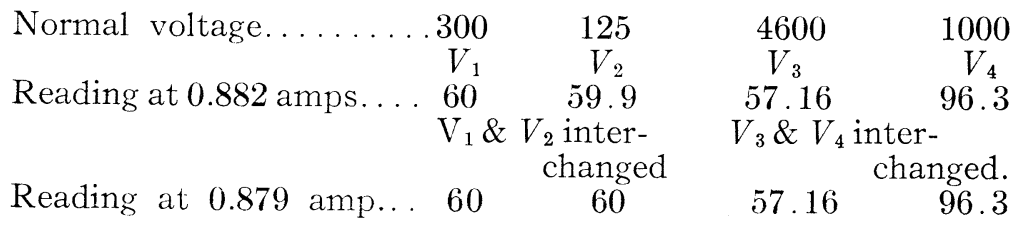

These readings were repeated and checked many times, with no appreciable difference in results. All taps on the voltmeter coil gave similar results.

One volt corresponds to two divisions on scale, one-tenth 
division being the extreme limit of observation, and probably beyond the accuracy of the instrument, or observer.

The voltages from transformation ratios of low voltage windings and potential transformer are as follows:

$$
\begin{aligned}
& V_{3}=37,300 \text { volts } \\
& V_{4}=60,200
\end{aligned}
$$

The high voltage as determined by all the readings is therefore:

$$
\begin{aligned}
& V_{1} \ldots \ldots \ldots 60,000 \\
& V_{2} \ldots \ldots \ldots 59,900-60,000 \\
& V_{3} \ldots \ldots \ldots 37,300 \\
& V_{4} \ldots \ldots \ldots 60,200
\end{aligned}
$$

Voltage was fairly steady, but as each observer had to read two instruments, the observations are hardly reliable to 0.1 volt. Other readings of $V_{4}$ gave 60,075 volts.

The greatest care was taken in reading $V_{1}$ and $V_{2}$ on the voltmeter coils, the low-tension voltage being of less interest. The small potential transformers may also have slight errors. The voltmeter coil in the 125,000 -volt transformer should be perfectly correct, since operation is at half voltage and no load. It is thus seen that the error in the voltmeter coil of the 300,000volt transformer is zero or so small as to be indeterminate by any ordinary methods, and therefore negligible.

On the other hand, the rise in voltage due to the capacity load is from 37,300 volts (measured on low voltage terminals) to 60,000 volts or 60.9 per cent (22,700 volts absolute).

These results show that the voltmeter coil is certainly accurate within $1 / 10$ per cent, and probably much less on full load, normal voltage and zero power factor leading. It would undoubtedly be equally good on lagging load, but this is never encountered in practise.

Similar tests were made at no load. The following results represent the largest apparent error:

$\begin{array}{cccc}V_{1} & V_{2} & V_{3} & V_{4} \\ \text { Reading at } 0 \text { amperes... .59.9 } & 59.8 & 91.6 & 95.8\end{array}$

High voltage from above

$$
\begin{aligned}
& V_{1}=59,900 \\
& V_{2}=59,800 \\
& V_{3}=59,800 \\
& V_{4}=59,870
\end{aligned}
$$

From all the readings taken the average error seems to be about +50 volts at 300,000 volts at both normal and zero load. This could be produced by an excess of two turns in the high voltage winding of 12,000 turns, or represented by one-tenth of a division on the voltmeter scale.

As a conclusion from all the results it is claimed that the error is less than ordinary minimum errors of observation and instruments, and less than those inherent in any other known method. of measuring high voltage. 